\title{
EXTRACTABILITY OF POLYPHENOLS FROM BLACK CURRANT, RED CURRANT AND GOOSEBERRY AND THEIR ANTIOXIDANT ACTIVITY
}

\author{
Eszter LaczKó-ZÖld, ${ }^{1}$ Andrea Komlósi, ${ }^{2}$ Timea Ülkei,${ }^{2}$ Erzsébet Fogarasi, ${ }^{3}$ \\ Mircea Croitoru, ${ }^{3 *}$ Ibolya FÜlöP, ${ }^{3}$ Erzsébet Domokos, ${ }^{4}$ \\ RUXANDRA ŞTEFĂNESCU ${ }^{1}$ and ERzSÉBEt VARGA ${ }^{1}$ \\ ${ }^{1}$ Department of Pharmacognosy and Phytotherapy, University of Medicine and \\ Pharmacy of Târgu Mureş, Gh. Marinescu nr. 38, 540139 Târgu Mureş, Romania \\ ${ }^{2}$ Faculty of Pharmacy, University of Medicine and Pharmacy of Târgu Mureş, student \\ ${ }^{3}$ Department of Toxicology and Biopharmacy, University of Medicine and Pharmacy of Târgu Mureş, \\ Gh. Marinescu nr. 38, 540139 Târgu Mureş, Romania \\ ${ }^{4}$ Department of Pharmaceutical Botany, University of Medicine and Pharmacy of Târgu Mureș, \\ Gh. Marinescu nr. 38, 540139 Târgu Mureş, Romania
}

(Received: October 24, 2017; accepted: January 15, 2018)

\begin{abstract}
In this study, we analyzed extracts of Ribes (black currant, red currant and gooseberry) fruits obtained with methanol, methanol $50 \%$ and water. For each extract total polyphenol content, total flavonoid content and total anthocyanin content was assessed. The antioxidant activity of extracts was evaluated by 1,1-Diphenyl-2-picrylhydrazyl (DPPH) and 2,2'-azino-bis(3-ethylbenzothiazoline-6-sulphonic acid) (ABTS) radical scavenging capacity and by the photo-chemiluminescence (PCL) method. Identification and quantification of individual phenolic compounds was performed by means of high performance liquid chromatograph coupled with diode array detector (HPLC-DAD) analyses. From each fruit, best extraction of polyphenols was obtained with methanol $50 \%$. In case of red currants and gooseberry there was no significant difference in flavonoids and anthocyanins extraction rate by the different extraction solvents. For black currants the methanol and methanol $50 \%$ extract presented the highest antioxidant activity. For red currants extracts with methanol $50 \%$ showed stronger antioxidant activity $\left(\mathrm{IC}_{50}=5.71 \mathrm{mg} / \mathrm{ml}\right.$ for $\mathrm{DPPH}, \mathrm{IC}_{50}=1.17 \mathrm{mg} / \mathrm{ml}$ for ABTS) than those with methanol or water. In case of gooseberry by the DPPH test the water extract proved to be the most active $\left(\mathrm{IC}_{50}=5.9 \mathrm{mg} / \mathrm{ml}\right)$. In the PCL test black currants methanol $50 \%$ extract was over 6 times more powerful as the ones from red currants. In case of gooseberries, water extract presented the highest antioxidant activity $(41.84 \mu \mathrm{mol} \mathrm{AAE} / \mathrm{g})$. In black currant cyanidin-3-glucoside was the major compound. Quercetin 3-O-glucoside was identified in each sample. From cinnamic acid derivatives neochlorogenic acid was present in black currants in the highest amount $(356.33 \mu \mathrm{g} / \mathrm{g})$.
\end{abstract}

Keywords: polyphenols - Ribes nigrum L. - Ribes rubrum L. - Ribes uva-crispa L. - antioxidant activity

\section{INTRODUCTION}

Dietary polyphenols, such as flavonoids, anthocyanins, phenolic acids, stilbenes and lignans, play an important role in the prevention and control of various diseases by balancing the oxidative and anti-oxidative factors in the human body.

*Corresponding author; e-mail address: croitoru.mircea@umftgm.ro 
Epidemiological studies suggest that a polyphenol rich diet may provide protection against coronary heart disease [1, 8, 14] and lung cancer [15]. Dietary flavonoid intake (such as quercetine, kaempherol and myricetine) proved to decrease the incidence of advanced stage prostate cancer [12].

Berries are especially rich sources of phenolic compounds including phenolic acids, tannins, and flavonoids such as anthocyanidins, flavonols and flavanols $[4,16,25]$.

Currants are a good source of vitamins (vitamins A, C, E, folic acid), provitamins and related compounds (carotene, lutein), minerals (calcium, selenium). They possess positive effects in dietary management of various diseases (hypertension, osteoporosis, inflammation, cancer and cardiovascular disease). The proposed health benefits are usually connected with phenolics as the main biologically active compounds of currants [31].

Currant fruits (Ribes species) are an important part of people's diet. They are known for their sour-tasting and are popular especially for their known health-promoting properties. Fruits of different Ribes species are consumed fresh or processed into syrup, juice, jams and extracts for food supplements [20].

Black currant (Ribes nigrum L., fam. Grossulariaceae) is a perennial shrub originating in North Europe and Asia. Among currants, blackcurrant berries are the richest in anthocyanins; major compounds are delphinidine-3-O-rutinoside and cyanidine3 -O-rutinoside $[2,5,11]$. Various studies proved the antioxidant activity $[5,19]$. Antiproliferative properties of blackcurrants were tested on human hepatocellular carcinoma cells [2], on murine melanoma, ovarian cancer and cervical cancer tumor cell lines [5]. According to the literature data, blackcurrant juice from Romania contains $580 \mathrm{mg} / 100 \mathrm{ml}$ total polyphenols (GAE), $84 \mathrm{mg} / 100 \mathrm{~g}$ total flavonoids (QE) and $116 \mathrm{mg} / 100 \mathrm{~g}$ total anthocyanin (CGE) [5]. Depending on cultivars and ripening stages, total phenolic content of black currants harvested in Slovenia varies from 393 to $734 \mathrm{mg} / 100 \mathrm{~g}$, anthocyanins from 196 to $461 \mathrm{mg} / 100 \mathrm{~g}$ [19].

Red currant (Ribes rubrum L.) and gooseberry (Ribes uva-crispa L.) are also shrubs from the Grossulariaceae family, the latter bearing spines on branches. Various investigations show that the quantity of phenolic metabolites in Ribes fruits is influenced by environmental conditions (season, degree of ripeness, growing conditions) and is also genetically controlled $[11,18,19,30]$. Therefore, literature data on phenolic compounds vary to a large degree. Mikulic-Petkovsek et al. [19] reported a total phenolic content for red currants from 104 to $327 \mathrm{mg} / 100 \mathrm{~g}$, for gooseberry from 101 to $192 \mathrm{mg} / 100 \mathrm{~g}$, depending on sampling dates and cultivars.

To our knowledge, except black currants, there is no comprehensive study on phenolic compounds of Ribes fruits harvested from Romania. Therefore our goal was to perform a comparative study of Romanian black currant, red currant and gooseberry fruits.

The present investigation deals with (i) determination of total phenolic content, flavonoid content, anthocyanin content and evaluation of the antioxidant activity by several in vitro methods of black currant, red currant and gooseberry fruits; (ii) determination of extractability of these phenolics in different solvents; (iii) identification of individual phenolic compounds by HPLC-DAD method. 


\section{MATERIALS AND METHODS}

\section{Chemicals and instrumentation}

The following standards were used for the identification and quantification of phenolic compounds: cyanidin 3-O-glucoside chloride (cyanidin 3-O- $\beta$-glucopyranoside chloride, kuromanin chloride), delphinidin chloride, malvidin-3-O-glucoside chloride (oenin chloride), pelargonidin chloride, chlorogenic acid, caffeic acid (3,4-dihydroxycinnamic acid), neochlorogenic acid (trans-5-O-caffeoylquinic acid), quercetin 3-rhamnoside (quercitrin), quercetin-3-O-glucose-6"-acetate, kaempferol 3-glucoside, quercetin 3-O-glucoside (quercetin 3- $\beta$-D-glucoside, isoquercitrin), quercetin 3-O-galactoside (hyperoside), quercetin-3-O-rutinoside (rutin), vitexin and vitexin2-O-rhamnoside from Roth (Carl Roth GmbH, Karlsruhe, Germany), Cayman (Cayman Chemical Company, Michigan, USA) and Sigma-Aldrich (Germany). For the DPPH radical scavenging activity 1,1-Diphenyl-2-picrylhydrazyl (DPPH) and ascorbic acid were purchased from Sigma-Aldrich (Germany). For the ABTS radical scavenging activity 2,2'-azino-bis (3-ethylbenzothiazoline)-6 sulfonic acid diammonium salt, potassium persulfate and Trolox were obtained from Sigma-Aldrich (Germany). The solvents for extraction and the mobile phases were HPLC grade and purchased from Merck (Darmstadt, Germany). Water was double distilled and purified with the Direct-Q system (Millipore, Bedford, USA). For the total phenolic content, Folin-Ciocalteu phenol reagent (Scharlau, Spain), sodium carbonate (Alfa Aesar, Karlsruhe, Germany), gallic acid (Sigma) were used. For the total flavonoid content aluminum chloride hexahydrate (Chimopar, Romania) and sodium acetate (Carl Roth GmbH, Karlsruhe, Germany) were used. For the total anthocyanins hydrochloric acid (Carl Roth GmbH, Karlsruhe, Germany) and methanol (Merck) were used.

For spectrophotometric determinations a Specord 210 (Analytic Jena) was used.

Photochemiluminescense test was performed with Photochem ${ }^{\circledR}$ (Analytic Jena) apparatus using an ACW (antioxidative capacities of water-soluble compounds)-s KIT (400.801, Analytic Jena).

\section{Plant material}

Berry fruits of Ribes uva-crispa L. (syn. Ribes grossularia L., gooseberry), Ribes nigrum L. (blackcurrant) and Ribes rubrum L. (red currant) were harvested in July and August 2015 at full maturity from a local farmer's garden (Cornesti, Mures County, Romania). Collected samples were frozen and stored at $-20^{\circ} \mathrm{C}$ until analyses. All determinations were performed in triplicate. The results were expressed as mean \pm standard deviation (SD). 


\section{Extraction of phenolic compounds}

We prepared extracts using methanol, methanol $50 \%$ and water. The fruits were ground to a fine paste in a mortar and $5 \mathrm{~g}$ were extracted with $50 \mathrm{ml}$ solvent in an ultrasonic bath at $25{ }^{\circ} \mathrm{C}$ for 30 minutes. Extracts were filtered into a $50 \mathrm{ml}$ volumetric flask and diluted with extraction solvent to $50 \mathrm{ml}$. Extracts were filtered through a nylon membrane filter $(0.2 \mu \mathrm{m}, \mathrm{VWR}, \mathrm{USA})$ and transferred into a vial prior the HPLC analysis.

\section{Determination of total phenolic content (TPC)}

TPC was determined by the Folin-Ciocalteu method [28]. To $40 \mu 1$ of the sample extracts $3.16 \mathrm{ml}$ distilled water and $200 \mu \mathrm{l}$ Folin-Ciocalteu reagent were added and mixed well; after 5 minutes, $600 \mu \mathrm{l}$ sodium carbonate $(20 \% \mathrm{w} / \mathrm{v})$ was added. The mixture was allowed to stand at room temperature $\left(20^{\circ} \mathrm{C}\right)$ for 2 hours; absorbance was measured at $765 \mathrm{~nm}$. A standard curve was plotted using gallic acid $(\mathrm{y}=0.0972 \mathrm{x}-$ $0.0155, \mathrm{r}^{2}=0.9963$ ) and the results were expressed as $\mathrm{mg}$ of gallic acid equivalents (GAE) per 100 gram fresh weight of fruit.

\section{Determination of total flavonoid content (TFC)}

For determination of the total flavonoid content of extracts, a colorimetric method was used described by the Romanian Pharmacopoeia [34], slightly modified. To 500 $\mu \mathrm{l}$ extract $1 \mathrm{ml}$ sodium acetate $(10 \% \mathrm{w} / \mathrm{v}), 600 \mu \mathrm{l} \mathrm{AlCl} 3(2.5 \%, \mathrm{w} / \mathrm{v}), 1.4 \mathrm{ml}$ methanol and $1.5 \mathrm{ml}$ water were added. The extracts were mixed and allowed to stand for 15 minutes at room temperature $\left(20^{\circ} \mathrm{C}\right)$ before measuring the absorbance at $430 \mathrm{~nm}$. The calibration curve was prepared with quercetin $\left(y=0.07 x-0.0726, r^{2}=0.9979\right)$ and results were expressed as $\mathrm{mg}$ of quercetin equivalents (QE) per 100 gram fresh weight of fruit.

\section{Determination of total anthocyanin content (TAC)}

Anthocyanins were measured by colorimetric method according to the European Pharmacopoeia $7^{\text {th }}$ Edition [33]. From extracts 5-fold or 50-fold dilutions were prepared in $0.1 \%(\mathrm{v} / \mathrm{v})$ solution of hydrochloric acid in methanol. The absorbance of solutions was measured at $528 \mathrm{~nm}$, using a $0.1 \%(\mathrm{v} / \mathrm{v})$ solution of hydrochloric acid in methanol as the compensation liquid. Results were expressed as mg cyanidin 3-O-glucoside chloride (CG) per $100 \mathrm{~g}$ fresh weight of fruit. 


\section{DPPH radical scavenging activity}

The antioxidant activity was evaluated by the DPPH-assay, according to the method developed by Brand-Williams et al. [3] with some modifications. Briefly, a solution of $1 \mathrm{mM}$ DPPH in methanol was prepared and diluted fresh to $0.1 \mathrm{mM}$. Absorbance of the solution was adjusted to $0.650 \pm 0.020$ at $517 \mathrm{~nm}$. Then, $200 \mu \mathrm{L}$ of sample or standard were mixed with $2800 \mu \mathrm{L}$ DPPH solution. The decrease of absorbance was measured at $517 \mathrm{~nm}$ after 6 min. The blank solution contained the same amount of DPPH reagent and $200 \mu \mathrm{L}$ of methanol. The percent of DPPH inhibition was calculated as follows:

$$
\text { DPPH inhibition } \%=\left(\mathrm{A}_{\mathrm{c}}-\mathrm{A}_{\mathrm{s}} / \mathrm{A}_{\mathrm{c}}\right) \times 100
$$

where $A_{c}$ is the absorbance of the control, $A_{s}$ is the absorbance of the sample. Ascorbic acid was used as reference and each test was performed in triplicate. Calculated $\mathrm{IC}_{50}$ represents the concentration of antioxidant required to decrease the DPPH amount by $50 \%$.

\section{ABTS radical scavenging activity}

The antioxidant activity was evaluated also with the ABTS method described by Re et al. [24] with slight modification. ABTS radical cation $\left(\mathrm{ABTS}^{\bullet+}\right)$ was produced by reacting $7 \mathrm{mM}$ ABTS solution with $2.45 \mathrm{mM}$ potassium persulfate and allowing the mixture to stand in the dark at room temperature for $12-16 \mathrm{~h}$ before use. The ABTS $\bullet+$ solution was diluted with methanol to an absorbance of $0.70( \pm 0.02)$ at $734 \mathrm{~nm}$. Trolox was used as antioxidant standard. After addition of 10-100 $\mu \mathrm{L}$ of sample or trolox standard to $2.5 \mathrm{~mL}$ of diluted $\mathrm{ABTS}^{\bullet+}$ solution, absorbance at $734 \mathrm{~nm}$ was measured at 6 minutes.

\section{Determination of radical scavenging activity with PCL method}

The superoxide-anion radical scavenging capacity was evaluated by photo-chemiluminescence method (PCL). This includes the photochemical generation of superoxide radical and its chemiluminometric detection. The antioxidative capacity of the sample is quantified by comparison with the standard and the results are given in $\mu \mathrm{mol}$ equivalent units of ascorbic acid. The Photochem ACW-s (antioxidative capacities of water-soluble compounds) assay kit contains: Reagent 1 (R1) - ACW-diluent samples solvent, Reagent 2 (R2) - reaction buffer, Reagent 3 (R3) - stock solution of photo sensitizer and detection reagent, Reagent 4 (R4) - calibration standard of ascorbic acid (AA). The working solution from R3 and R4 were prepared as recommended by the producer, Analytic Jena $[35,36]$. From the extracts 10 -fold or 50 -fold dilution were prepared with $\mathrm{R} 1$. The composition of reaction mixtures were: $20 \mu 1$ diluted 
samples completed to $1500 \mu 1$ with R1, $1000 \mu 1 \mathrm{R} 2$ and $25 \mu 1 \mathrm{R} 3$. After thorough mixing the samples were introduced to the Photochem ${ }^{2}$. The calibration mixture consisted of: 5-10-15-20-25-30 or 50 $\mu 1 \mathrm{R} 4$ working solution completed to $1500 \mu 1$ with R1, $1000 \mu \mathrm{l}$ R2 and $25 \mu 1 \mathrm{R} 3$. The blank solution contained $1500 \mu \mathrm{l}$ R1, 1000 $\mu 1 \mathrm{R} 2$ and $25 \mu \mathrm{R} 3$. The modification of luminescence signal was followed over 4 minutes. Each test was performed in triplicate and the equivalent units of ascorbic acid were calculated automatically by PCL soft, and the results were expressed as $\mu \mathrm{mol}$ AA equivalent $/ \mathrm{ml}$ extract.

\section{Identification and quantification of individual phenolic compounds by $R P-H P L C-D A D$}

High performance liquid chromatography was carried out using a Merck HPLC system equipped with a quaternary pump Merck Hitachi L-7100, an Merck Hitachi L-7200 autosampler and a Merck Hitachi L-7360 column thermostat, Merck Hitachi L-7000 interface. Separation was performed at ambient temperature with a Nucleodur C18 column $(3 \mu \mathrm{m} ; 150 \mathrm{~mm} \times 4.6 \mathrm{~mm}$; Macherey-Nagel) using a mobile phase consisting of solvent A $(20 \mathrm{mmol} / \mathrm{l}$ phosphate buffer, $\mathrm{pH}=2.5)$ and solvent $\mathrm{B}$ (acetonitrile) with the gradient program shown in Table 1. Injection volume was $100 \mu \mathrm{L}$ and the flow rate $0.55 \mathrm{~mL} / \mathrm{min}$. Analytes were detected at 280,370 and $520 \mathrm{~nm}$ with a Merck Hitachi L-7455 DAD detector. Identification and peak assignments were done based on their retention times and UV-VIS spectra comparing with authentic standards. Concentrations of phenolic compounds were calculated from peak areas of the sample and the corresponding standards calibration curve. The concentrations were expressed in $\mu \mathrm{g} / \mathrm{g}$.

Table 1

Gradient program for the mobile phase

\begin{tabular}{|c|c|c|}
\hline Time $(\mathrm{min})$ & Mobile phase $-\mathrm{A}(\% \mathrm{v} / \mathrm{v})$ & Mobile phase $-\mathrm{B}(\% \mathrm{v} / \mathrm{v})$ \\
\hline 0 & 95 & 5 \\
\hline 5 & 95 & 24 \\
\hline 90 & 76 & 5 \\
\hline
\end{tabular}

\section{Statistical analysis}

Results were expressed as mean \pm standard deviation. Statistical differences were evaluated with one-way analysis of variance (ANOVA) or with Student $t$-test. Tukey's multiple comparison test was used as post hoc analysis. Differences at the level $\mathrm{p}<0.05$ were considered to be significant. $\mathrm{IC}_{50}$ for DPPH and ABTS tests and correlations were calculated by GraphPad Prism5 software. 


\section{RESULTS}

In this study, we analyzed extracts of black currant, red currant and gooseberry fruits obtained with methanol, methanol 50\% and water, respectively. For each extract total polyphenol content, total flavonoid content and total anthocyanin content was assessed. The antioxidant activity of extracts was evaluated by DPPH and ABTS radical scavenging capacity and by the photo-chemiluminescence method. Identification and quantification of individual phenolic compounds were performed by means of HPLC-DAD analyses.

\section{Total polyphenol content (TPC), total flavonoid content (TFC) and total anthocyanin content (TAC)}

The values obtained for total polyphenol, flavonoid and anthocyanin content of methanol, methanol 50\% and water extracts are given in Table 2. From each fruit, polyphenols were best extracted with methanol $50 \%$, followed by methanol; water being the least effective extraction solvent (Table 2). In case of black currants, extraction of flavonoids and anthocyanins presented the same tendency as polyphenols, the best extraction was achieved with methanol $50 \%$.

In case of red currants and gooseberry there were no significant differences in the extraction rates of flavonoids and anthocyanins by the different extraction solvents (Table 2).

Table 2

Total polyphenol content (TPC), total flavonoid content (TFC) and total anthocyanin content (TAC) of black currants (Ribes nigrum L.), red currants (Ribes rubrum L.) and gooseberry (Ribes uva crispa L.) determined in different extracts

\begin{tabular}{|c|l|c|c|c|}
\hline \multirow{2}{*}{ Fruit } & Extraction solvent & $\begin{array}{c}\text { TPC } \\
\text { GAE mg/100 g fw }\end{array}$ & $\begin{array}{c}\text { TFC } \\
\text { QE mg/100 g fw }\end{array}$ & $\begin{array}{c}\text { TAC } \\
\text { CGE mg/100 g fw }\end{array}$ \\
\hline \multirow{3}{*}{$\begin{array}{l}\text { Ribes } \\
\text { nigrum }\end{array}$} & Methanol & $169.88 \pm 27.6^{\mathrm{bcd}}$ & $86.99 \pm 24.7^{\mathrm{b}}$ & $222.7 \pm 38^{\mathrm{a}}$ \\
\cline { 2 - 5 } & Methanol $50 \%$ & $225.93 \pm 52.4^{\mathrm{c}}$ & $126.11 \pm 14.6$ & $327.34 \pm 22$ \\
\cline { 2 - 5 } & Water & $133.57 \pm 1.8^{\mathrm{abd}}$ & $21.92 \pm 6.7^{\mathrm{a}}$ & $187.66 \pm 7.6^{\mathrm{a}}$ \\
\hline \multirow{3}{*}{$\begin{array}{l}\text { Ribes } \\
\text { rubrum }\end{array}$} & Methanol & $110.99 \pm 17.3^{\mathrm{ab}}$ & $37.72 \pm 4.04^{\mathrm{ac}}$ & $17.66 \pm 0.01^{\mathrm{b}}$ \\
\cline { 2 - 5 } & Methanol 50\% & $192.98 \pm 8.2^{\mathrm{cd}}$ & $39.98 \pm 6.1^{\mathrm{ac}}$ & $21.26 \pm 0.07^{\mathrm{b}}$ \\
\cline { 2 - 5 } & Water & $72.76 \pm 7.6^{\mathrm{a}}$ & $40.08 \pm 16.2^{\mathrm{ac}}$ & $18.92 \pm 0.82^{\mathrm{b}}$ \\
\hline \multirow{3}{*}{$\begin{array}{l}\text { Ribes } \\
\text { uva crispa }\end{array}$} & Methanol & $153.37 \pm 11.8^{\mathrm{bd}}$ & $59.58 \pm 8.17^{\mathrm{bc}}$ & $6.82 \pm 0.16^{\mathrm{b}}$ \\
\cline { 2 - 5 } & Methanol $50 \%$ & $195.22 \pm 10.7^{\mathrm{cd}}$ & $65.03 \pm 5.34^{\mathrm{bc}}$ & $6.83 \pm 0.04^{\mathrm{b}}$ \\
\cline { 2 - 5 } & $122.28 \pm 2.3^{\mathrm{ab}}$ & $55.99 \pm 0.84^{\mathrm{abc}}$ & $5.69 \pm 0.1^{\mathrm{b}}$ \\
\hline
\end{tabular}

Data are expressed as mean \pm standard deviation. Values within the same column followed by different letters were significantly different $(\mathrm{p}<0.05)$. $\mathrm{fw}$ - fresh weight; GAE - gallic acid equivalent; $\mathrm{QE}$ - quercetin equivalent; CGE - cyanidin 3-O-glucoside chloride equivalent. 
Table 3

In vitro antioxidant activity of black currants (Ribes nigrum L.), red currants (Ribes rubrum L.) and gooseberry (Ribes uva crispa L.) in three different extracts

\begin{tabular}{|c|c|c|c|c|}
\hline Fruit & Extraction solvent & $\begin{array}{c}\text { DPPH } \\
\mathrm{IC}_{50} \mathrm{mg} / \mathrm{ml}\end{array}$ & $\begin{array}{c}\text { ABTS } \\
\mathrm{IC}_{50} \mathrm{mg} / \mathrm{ml}\end{array}$ & $\begin{array}{c}\text { PCL } \\
\mu \mathrm{mol} \text { AAE } / g \text { fruit }\end{array}$ \\
\hline \multirow{3}{*}{$\begin{array}{l}\text { Ribes } \\
\text { nigrum }\end{array}$} & Methanol & $1.77 \pm 0.08^{\mathrm{ad}}$ & $0.47 \pm 0.03^{\mathrm{b}}$ & $83.28 \pm 7.89^{\mathrm{a}}$ \\
\hline & Methanol 50\% & $1.90 \pm 0.12^{\mathrm{ad}}$ & $0.49 \pm 0.06^{\mathrm{b}}$ & $146.54 \pm 1.36$ \\
\hline & $\mathrm{H}_{2} \mathrm{O}$ & $3.67 \pm 0.36^{\mathrm{abcd}}$ & $0.68 \pm 0.04^{b}$ & $86.91 \pm 5.29^{\mathrm{a}}$ \\
\hline \multirow{3}{*}{$\begin{array}{l}\text { Ribes } \\
\text { rubrum }\end{array}$} & Methanol & $34.26 \pm 4.3$ & $1.36 \pm 0.13^{\mathrm{a}}$ & $13.9 \pm 1.62^{b}$ \\
\hline & Methanol $50 \%$ & $5.72 \pm 0.61^{\mathrm{abd}}$ & $1.17 \pm 0.08^{\mathrm{a}}$ & $23.98 \pm 1.25^{\mathrm{b}}$ \\
\hline & $\mathrm{H}_{2} \mathrm{O}$ & $8.33 \pm 0.89^{\mathrm{bd}}$ & $2.88 \pm 0.06$ & $16.71 \pm 2.49^{b}$ \\
\hline \multirow{3}{*}{$\begin{array}{l}\text { Ribes } \\
\text { uva crispa }\end{array}$} & Methanol & $17.63 \pm 3.1^{\mathrm{c}}$ & $4.26 \pm 0.42$ & $18.95 \pm 2.07^{\mathrm{b}}$ \\
\hline & Methanol 50\% & $12.17 \pm 1.12$ & $0.41 \pm 0.01^{\mathrm{b}}$ & $21.14 \pm 2.98^{b}$ \\
\hline & $\mathrm{H}_{2} \mathrm{O}$ & $5.9 \pm 0.98^{d}$ & $1.93 \pm 0.04$ & $41.87 \pm 0.82$ \\
\hline
\end{tabular}

Data are expressed as mean \pm standard deviation. Values within the same column followed by different letters were significantly different $(\mathrm{p}<0.05)$. AAE - ascorbic acid equivalent.

Results of the antioxidant activity tests are presented in Table 3. For the DPPH and ABTS tests $\mathrm{IC}_{50}$ were calculated; the lower these values, the stronger the antioxidant activity. Among black currant extracts, those obtained with methanol and methanol $50 \%$ displayed higher antioxidant activity (lower $\mathrm{IC}_{50}$ ) in the DPPH and ABTS tests (Table 3). For red currants, the $50 \%$ methanol extracts showed stronger antioxidant activity $\left(\mathrm{IC}_{50}=5.71 \mathrm{mg} / \mathrm{ml}\right.$ for DPPH, $\mathrm{IC}_{50}=1.17 \mathrm{mg} / \mathrm{ml}$ for ABTS) compared to the aqueous extracts. In case of gooseberry, according to the DPPH test the water extract proved to be the most active $\left(\mathrm{IC}_{50}=5.9 \mathrm{mg} / \mathrm{ml}\right)$, while according to the ABTS test the methanol 50\% extract shows the highest antioxidant activity $\left(\mathrm{IC}_{50}=0.41 \mathrm{mg} / \mathrm{ml}\right)$.

For the photo-chemiluminescence method $\mu \mathrm{mol}$ ascorbic acid equivalent (AAE) was calculated by the PCL software. Higher AAE value means higher antioxidant activity. For black and red currants, extracts obtained with methanol $50 \%$ showed the highest antioxidant capacity; black currants being over 6 times more powerful as red currants. In case of gooseberries, water extract showed the highest antioxidant activity (Table 3$)$.

\section{Identification and quantification of individual phenolic compounds by $R P-H P L C-D A D$}

Identified compounds and their quantities are given in Table 4. Representative chromatograms are shown in Figures 1 and 2. Three anthocyanins were identified in black currant, with cyanidin-3-O-glucoside being the major compound. This compound was detected in lower amounts also in the other two samples. Among flavonols 


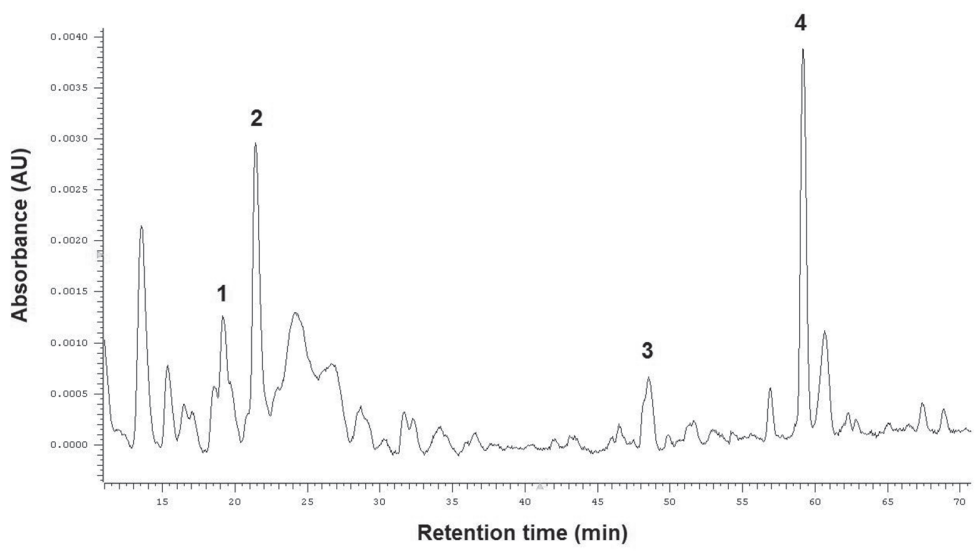

Fig. 1. HPLC chromatogram recorded at $280 \mathrm{~nm}$ corresponding to the phenolic profile of Ribes uva crispa fruits. 1 - Neochlorogenic acid, 2 - Cyanidin 3-O-glucoside, 3 - Quercetin 3-O-glucoside, 4 Quercetin-3-rhamnoside

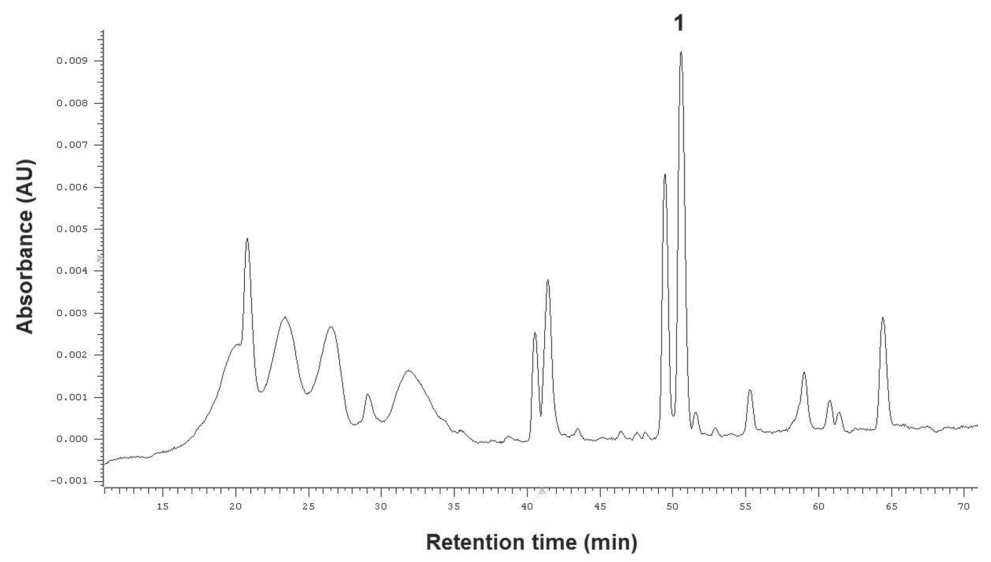

Fig. 2. HPLC chromatogram recorded at $370 \mathrm{~nm}$ corresponding to the flavonoid profile of Ribes nigrum fruits. The main compound is isoquercitrin (Quercetin 3-O-glucoside) (1)

quercetin 3-O-glucoside (isoquercitrin) was identified in each sample. Similarly to cyanidin-3-O-glucoside, this compound was present in the highest amounts in black currant extracts. From cinnamic acid derivatives neochlorogenic acid was present in black currants in the highest amount, small quantity was measured in gooseberry, and it was not detected in red currants. 
Table 4

Contents of phenolic compounds in black currants (Ribes nigrum L.), red currants (Ribes rubrum L.) and gooseberry (Ribes uva crispa L.) determined by RP-HPLC-DAD and expressed in microgram per gram fresh weight

\begin{tabular}{|c|c|c|c|}
\hline \multirow{2}{*}{ Phenolic compounds } & Ribes nigrum & Ribes rubrum & Ribes uva crispa \\
\hline & \multicolumn{3}{|c|}{$\mu \mathrm{g} / \mathrm{g}$ fw } \\
\hline \multicolumn{4}{|l|}{ Anthocyanins } \\
\hline Cyanidin 3-O-glucoside & $65.99 \pm 8.64$ & $16.97 \pm 0.23^{\mathrm{a}}$ & $9.57 \pm 1.66^{\mathrm{a}}$ \\
\hline Delphinidin & $13.81 \pm 0.91$ & $\mathrm{nd}^{*}$ & nd \\
\hline \multicolumn{4}{|l|}{ Flavonols } \\
\hline Quercetin-3-O-rutinoside & nd & $7.2 \pm 0.85$ & nd \\
\hline Quercetin 3-O-glucoside & $106.25 \pm 22.56$ & $39.96 \pm 4.08^{a}$ & $43.55 \pm 2.01^{\mathrm{a}}$ \\
\hline Quercetin-3-rhamnoside & nd & nd & $67.42 \pm 6.53$ \\
\hline \multicolumn{4}{|l|}{ Cinnamic acid derivatives } \\
\hline Neochlorogenic acid & $356.33 \pm 24.02$ & nd & $2.31 \pm 0.74^{\mathrm{a}}$ \\
\hline Caffeic acid & $52.8 \pm 3.57$ & nd & nd \\
\hline
\end{tabular}

*Not detected. Data are expressed as mean \pm standard deviation. Values within the same row followed by different letters were significantly different $(\mathrm{p}<0.05)$. fw - fresh weight.

\section{DISCUSSION}

Although many authors are on the opinion that the Folin-Ciocalteu assay can be considered as an antioxidant capacity measuring technique [9, 23, 25], this method is still used to determine total phenol content in many plant foods and fruits [10, 19, 22, 29]. Since phenolics are the most abundant antioxidants in most plants, it gives a rough approach of the phenolic content in most cases [9].

In order to compare our results with previous findings on Ribes fruits, we also used the Folin-Ciocalteu assay to determine the total phenolic content. In all samples examined, higher levels of total phenolic content were obtained when extraction was performed with methanol $50 \%$, compared to those obtained with methanol or water. The total polyphenol content of Ribes rubrum and Ribes uva-crispa is in accordance with those of Mikulic-Petkovsek et al. [19] and Djordjević et al. [6], who reported a value between 67.2-153.4 mg GAE/100 g. For Ribes nigrum Mikulic-Petkovsek et al. [19] and Diaconeasa et al. [5] reported higher polyphenol content than those obtained in our study. The difference could be attributed to the extraction method used in juice preparation by these authors $[5,19]$ and also explained by genetic differences, growth location and environmental factors [17, 21, 30, 32].

For blackcurrants the total flavonoid content is in accordance with values reported by Diaconeasa et al. ( $84.6 \mathrm{mg} / 100 \mathrm{~g} \mathrm{fw})$ [5]. The total anthocyanin content was higher than previously reported from Romania (116 mg/100 g fw) [5], and is in 
accordance with Mikulic-Petkovsek et al. [19], and the data reported by Paunovic et al. [21]. The total anthocyanin content of red currants and gooseberry is also in accordance with values reported previously $[6,7,19]$.

All of the identified flavonoids by HPLC-DAD were previously reported by Mikulic-Petkovsek et al. [19]. As it was expected glycosides of quercetin were identified in all samples, many authors report quercetin as the dominant aglycone in Ribes species $[13,17,21,30,32]$. Quantity of rutin in fruits of Ribes rubrum $(7.2 \mu \mathrm{g} / \mathrm{g})$ is in accordance with values reported by Gavrilova et al. $(4.7-18.9 \mu \mathrm{g} / \mathrm{g})$ [11]. Quantity of cyanidin-3-O-glucoside in the black currants is in accordance with those reported by Gavrilova et al., who reported between 28.9-136.2 $\mu \mathrm{g} / \mathrm{g}$ [11]. Mikulic-Petkovsek et al. also reported neochlorogenic acid only in fruits of Ribes nigrum and Ribes uvacrispa [19].

\section{Correlation between phenolic content and antioxidant activity}

Similar in vitro antioxidant tests were performed by other research teams, too. $\mathrm{IC}_{50}$ values of the DPPH test are in accordance with previous findings [6, 7, 27].

The correlation of total phenolic content, total flavonoid content and anthocyanin content with DPPH, ABTS and PCL activities is given is Table 5. In case of Ribes nigrum the correlation was higher between total phenolic content and PCL activity than that of total phenolic content and DPPH or ABTS activity (Table 5). The total flavonoid content presented higher correlation with DPPH and ABTS activity than with PCL activity, while the total anthocyanin content showed high correlation only with the PCL activity $\left(\mathrm{R}^{2}=0.91\right)$.

Table 5

Correlation analysis of antioxidant activity (DPPH, ABTS, PCL) values with total phenolic content (TPC), total flavonoid content (TFC) and total anthocyanin content (TAC) of Ribes nigrum, Ribes rubrum and Ribes uva crispa fruits

\begin{tabular}{|l|c|c|c|c|}
\hline \multirow{5}{*}{ Ribes nigrum } & & DPPH & \multicolumn{2}{|c|}{ PBTS } \\
\cline { 2 - 5 } & & \multicolumn{2}{|c|}{$\mathrm{R}^{2}$} & $0.55^{*}$ \\
\hline \multirow{3}{*}{ Ribes rubrum } & TPC & $0.57^{*}$ & $0.79 * *$ & $0.56^{*}$ \\
\cline { 2 - 5 } & TFC & $0.81^{* * *}$ & 0.39 & $0.91 * * *$ \\
\cline { 2 - 5 } & TAC & 0.42 & $0.66^{* *}$ & $0.69 * *$ \\
\hline \multirow{3}{*}{ Ribes uva crispa } & TPC & 0.08 & 0.18 & $0.47 *$ \\
\cline { 2 - 5 } & TFC & $0.98^{* * *}$ & 0.08 & $0.99 * * *$ \\
\cline { 2 - 5 } & TAC & $0.66^{* *}$ & 0.21 & $0.58^{*}$ \\
\cline { 2 - 5 } & TPC & 0.21 & 0.24 & $0.55^{*}$ \\
\cline { 2 - 5 } & TFC & 0.18 & 0.01 & $0.99 * * *$ \\
\hline
\end{tabular}

$* \mathrm{p}<0.05 ; * * \mathrm{p}<0.01 ; * * * \mathrm{p}<0.001$. 
In case of Ribes rubrum the total phenolic content showed moderate correlation with ABTS and PCL activity; the total flavonoid content was in high correlation with DPPH activity; total anthocyanin content presented high correlation with PCL activity.

For the Ribes uva crispa extracts moderate correlation was observed between total anthocyanin content and DPPH, high correlation between total anthocyanin content and PCL activity, respectively.

Table 6 shows how the antioxidant activity measuring techniques correlate with each other. In Ribes nigrum extracts there was a high correlation between DPPH and ABTS techniques $(\mathrm{p}<0.001)$. Between DPPH and PCL techniques there was a moderate correlation $(\mathrm{p}<0.05)$ in case of Ribes rubrum extracts; for Ribes uva crispa extracts high correlation was observed $(\mathrm{p}<0.001)$.

Even though polyphenols were extracted with maximal rate by methanol $50 \%$, in the antioxidant activity tests not always these extracts presented the highest activity. This fact can be explained by the involvement of multiple substances in the development of the activity.

Prior et al. [23] concluded that the evaluation of overall antioxidant capacity may require multiple assays to generate an antioxidant profile. Our results highlight once again the importance of testing the antioxidant activity of extracts by various methods, this being necessary to get an overview on antioxidant capacity of products.

Based on these results PCL method is a good choice in ranking Ribes extracts according to their antioxidant effect. This method shows correlation with all classes of active substances. To complete the image of the antioxidant activity, as a second method the ABTS test should be performed.

The goal of this study was the evaluation of phenolic compounds in Ribes fruits harvested in Romania, determination of their extractability in different solvents and evaluation of antioxidant activity. Based on the results of these findings, it can be concluded that the extract of black currants obtained with methanol $50 \%$ are the richest source of antioxidant. Red currants and gooseberries are also a minor source of phenolic substances which can contribute to their antioxidant activity. Our results

Table 6

Correlation of different antioxidant capacity measuring techniques to each other

\begin{tabular}{|c|c|c|c|}
\hline \multirow{3}{*}{ Ribes nigrum } & \multirow[b]{3}{*}{ DPPH } & ABTS & PCL \\
\hline & & \multicolumn{2}{|c|}{$\mathrm{R}^{2}$} \\
\hline & & $0.99 * * *$ & 0.15 \\
\hline Ribes rubrum & DPPH & 0.10 & $0.59^{*}$ \\
\hline Ribes uva crispa & DPPH & 0.32 & $0.85^{* * *}$ \\
\hline Ribes nigrum & ABTS & - & 0.14 \\
\hline Ribes rubrum & ABTS & - & 0.12 \\
\hline Ribes uva crispa & ABTS & - & 0.04 \\
\hline
\end{tabular}

${ }^{*} \mathrm{p}<0.05 ; * * * \mathrm{p}<0.001$. 
clearly indicate that the antioxidant activity cannot be correlated only with the total polyphenol content of extracts, because it is due to the complex activity of a variety of compounds, including flavonoids and anthocyanins.

\section{ACKNOWLEDGEMENT}

We thank the Hungarian Academy of Sciences and Studium Prospero Foundation (0350/26.02.2016) for the financial support.

\section{REFERENCES}

1. Arts, I., Hollman, P. (2005) Polyphenols and disease risk in epidemiologic studies. Am. J. Clin. Nutr. 81, 317-325.

2. Bishayee, A., Háznagy-Radnai, E., Mbimba, T., Sipos, P., Morazzoni, P., Darvesh, A. S., Bhatia, D., Hohmann, J. (2010) Anthocyanin-rich black currant extract suppresses the growth of human hepatocellular carcinoma cells. Nat. Prod. Commun. 5, 1613-1618.

3. Brand-Williams, W., Cuvelier, M. E., Breset, C. (1995) Use of a free radical method to evaluate antioxidant activity. LWT Food Sci. Tehnol. 28, 25-30.

4. Cieslik, E., Greda, A., Adamus, W. (2006) Contents of polyphenols in fruits and vegetables. Food Chem. 94, 135-142.

5. Diaconeasa, Z., Leopold, L., Rugină, D., Ayvaz, H., Socaciu, C. (2015) Antiproliferative and antioxidant properties of anthocyanin rich extracts from blueberry and blackcurrant juice. Int. J. Mol. Sci. 16, 2352-2365.

6. Djordjević, B., Šavikin, K., Zdunić, G., Janković, T., Vulić, T., Oparnica, C., Radivojevik, D. (2010) Biochemical properties of red currant varieties in relation to storage, Plant Foods Hum. Nutr. 65, 326-332.

7. Djordjević, B., Šavikin, K., Zdunić, G., Janković, T., Vulić, T., Pljevljakušic, D., Oparnica, C. (2013) Biochemical properties of the fresh and frozen black currants and juices. J. Med. Food. 16, 73-81.

8. Du, G., Sun, L., Zhao, R., Du, L., Song, J., Zhang, L., He, G., Zhang, Y., Zhang, J. (2016) Polyphenols: potential source of drugs for the treatment of ischaemic heart disease. Pharmacol. Therap. 162, 23-34.

9. Everette, J. D., Bryant, Q. M., Green, A. M., Abbey, Y. A., Wangila, G. W., Walker, R. B. (2010) A thorough study of reactivity of various compound classes towards the Folin-Ciocalteu reagent. J. Agric. Food Chem. 58, 8139-8144.

10. Floegel, A., Kim, D. O., Chung, S. J., Koo, S. I., Chun, O. K. (2011) Comparison of ABTS/DPPH assay to measure antioxidant capacity in popular antioxidant-rich US foods. J. Food Compos. Anal. 24, 1043-1048.

11. Gavrilova, V., Kajd-Zanoska, M., Gjamovski, V., Stefova, M. (2011) Separation, characterization and quantification of phenolic compounds in blueberries and red and black currants by HPLC-DAD-ESIMS. J. Agric. Food Chem. 59, 4009-4018.

12. Geybels, M. S., Verhage, B. A. J., Arts, I. C. W., van Schooten, F. J., Goldbohm, R. A., van den Brandt, P. A. (2013) Dietary flavonoid intake, black tea consumption, and risk of overall and advanced stage prostate cancer. Am. J. Epidemiol. 177, 1388-1398.

13. Häkkinen, S. H., Kärenlampi, S. O., Heinonen, I. M., Mykkänen, H. M., Törrönen, A. R. (1999) Content of the flavonols quercetin, myricetin, and kaempferol in 25 edible berries. J. Agric. Food Chem. 47, 2274-2279.

14. Knekt, P., Reunanen, A., Jarvien, R., Maatela, J. (1996) Flavonoid intake and coronary mortality in Finland: a cohort study. BMJ 312, 478-481.

15. Knekt, P., Jarvinen, R., Seppanen, R., Heliovaara, M., Teppo, L. (1997) Dietary flavonoids and the risk of lung cancer and other malignant neoplasms. Am. J. Epidemiol. 146, 223-230. 
16. Liu, R. H. (2013) Dietary bioactive compounds and their health implications. J. Food Sci. 78, 18-25.

17. Mattila, P., H., Hellström, J., Karhu, S., Pihlava, J. M., Vetetäinen, M. (2016) High variability in flavonoid contents and composition between deifferent North-European currants (Ribes spp.) varieties. Food Chem. 204, 14-20.

18. Mikulic-Petkovsec, M., Schmitzer, V., Slatnar, A., Stampar, F., Veberic, R. (2012) Composition of sugars, organic acids and total phenolics in 25 wild or cultivated berry species. J. Food Sci. 77 , 1064-1070.

19. Mikulic-Petkovsek, M., Rescic, J., Schmitzer, V., Stampar, F., Slatnar, A., Koron, D., Veberic, R. (2015) Changes in fruit quality parameters of four Ribes species during ripening. Food Chem. 173, 363-374.

20. Milivojevik, J., Slatnar, A., Mikulic-Petkovsek, M., Stampar, F., Nikolic, M. (2012) The influence of early yield on the accumulation of major taste and health-related compounds in black and red currant cultivars (Ribes spp.). J. Agric. Food Chem. 60, 2682-2691.

21. Paunovic, S. M., Maskovic P., Nikolic M., Miletic, R. (2017) Bioactive compounds and antimicrobial activity of black currant (Ribes nigrum L.) berries and leaves extract obtained by different soil management system. Sci. Horticult. 222, 69-75.

22. Pinacho, R., Cavero, R. Y., Astiasaran, I., Ansorena, D., Calvo, M. I. (2015) Phenolic compounds of blackthorn (Prunus spinosa L.) and influence of in vitro digestion on their antioxidant capacity. J. Funct. Foods, 19, 49-62.

23. Prior, R. L., Wu, X., Schaich, K. (2005) Standardized methods for the determination of antioxidant capacity and phenolics in foods and dietary supplements. J. Agric. Food Chem. 53, 4290-4302.

24. Re, R., Pellegrini, N., Proteggente, A., Pannala, A., Yang, M., Rice-Evans, C. (1999) Antioxidant activity applying an improved ABTS radical cation decolorization assay. Free Radical Biol. Med. 26, 1231-1237.

25. Ruiz-Rodriguez, B. M., de Ancos, B., Sánchez-Moreno, C., Fernández-Ruiz, V., Sánchez-Mata, M. C., Cámara, M., Tardio, J. (2014) Wild blackthorn (Prunus spinosa L.) and hawthorn (Crataegus monogyna Jacq.) fruits as valuable sources of antioxidants. Fruits 69, 61-73.

26. Salvin, J. L., Loyd, B. (2012) Health benefits of fruits and vegetables. Adv. Nutr. 3, 506-516.

27. Šavikin, K., Zdunić, G., Janković, T., Tasić, S., Menković, N., Stević, T., Dordević, B. (2009) Phenolic content and radical scavengig capacity of berries and related jams from certified area in Serbia. Plant Foods Hum. Nutr. 64, 212-217.

28. Singleton, V. L., Rossi, J. A. (1965) Colorimetry of total phenolics with phosphomolybdic-phosphotungstic acid reagents. Amer. J. Enol. Viticult. 16, 144-158.

29. Spinola, V., Pinto, J., Castilho, P. C. (2015) Identification and quantification of phenolic compounds of selected fruits from Madeira Island by HPLC-ESI-MSn and screening for their antioxidant activity. Food Chem. 173, 14-30.

30. Vagiri, M., Ekholm, A., Öberg, E., Johansson, E., Andersson, S. C., Rumpunen, K. (2013) Phenols and ascorbic acid in black currants (Ribes nigrum L.): Variation due to genotype, location, and year. J. Agric. Food Chem. 61, 9298-9306.

31. Zdunić, G., Šavikin, K., Pljevljakušić, D., Djordjević, B. (2016) Black (Ribes nigrum L.) and Red Currant (Ribes rubrum L.) Cultivars. Chapter 5. In: Nutritional Composition of Fruit Cultivars, pp. $101-106$

32. Zheng, J., Yang, B., Ruusunen, V., Laaksonen, O., Tahvonen, R., Hellsten, J. (2012) Compositional differences of phenolic compounds between black currant (Ribes nigrum L.) cultivars and their response to latitude and weather conditions. J. Agric. Food Chem. 60, 6581-6593.

33. *** European Pharmacopoeia $7^{\text {th }}$ Edition, 2010, pp. 1070-1071.

34. *** Farmacopeea Română, Ed. X, Bucureşti, 1993, pp. 334-335.

35. *** Protocol for the Determination of Antioxidative Capacity of water soluble compounds (ACW) with PHOTOCHEM ${ }^{\circledR}$, code number: ACW-Kit, 2007.

36. https://www.analytik-jena.de/en/analytical-instrumentation/products/antioxidants.html 